\title{
Design Of Ku-Band Hexagonal Microstrip Patch Antenna With Linear And Circular Polarizations
}

\author{
Kadiyam Suresh $^{1}$, Dr. P. Siddaiah ${ }^{2}$ \\ M.Tech Student, Department of ECE, University College of Engineering and Technology, Acharya Nagarjuna \\ University, Guntur, India ${ }^{1}$ \\ Principal \& Professor, Department of ECE, University College of Engineering and Technology, Acharya Nagarjuna \\ University, Guntur, India ${ }^{2}$
}

\begin{abstract}
This paper presents two antennas, one is linearly polarized dual frequency hexagonal microstrip patch antenna and other is wide band circularly polarized hexagonal microstrip patch antenna. The presented antennas are designed for $\mathrm{Ku}$ band applications. Dual frequency is obtained by introducing a rectangular shaped slot on the hexagonal patch. Both antennas are simulated using HFSS 14.0 and performance measures of an antenna such as return loss, voltage standing wave ratio (VSWR), axial ratio, peak gain and radiation pattern are measured.
\end{abstract}

Key words: Hexagonal, slot, axial ratio, circular polarization, linear polarization.

\section{INTRODUCTION}

Antennas play very important role in the field of wireless communications. Some of them are Parabolic Reflectors, microstrip Antennas, Slot Antennas, and Folded Dipole Antennas. Each type of antenna is good in its own properties and usage. We can say antennas are the backbone for wireless communication without which the world could have not reached at this age of technology.

Microstrip patch antennas play a very significant role in today's world of wireless communication systems.. A Microstrip patch antenna is very simple in the construction using a conventional Microstrip fabrication technique. Rectangular and circular patch antennas are the most commonly used microstrip patch antennas. Dual characteristics, circular polarization, dual frequency operation, frequency agility, broad band width, feed line flexibility, beam scanning and triple band frequencies can be easily obtained from these patch antennas.

Micro strip antennas are widely used in the microwave frequency region because of their simplicity and compatibility with printed circuit technology, making them easy to manufacture. Generally a microstrip antenna or a patch antenna consists of a patch of metal on top of the grounded substrate. The substrate is made of a dielectric material.. Various methods are used to feed a micro strip antenna such as inset feed, coaxial feed, aperture coupled or slot coupled feed and proximity coupled feed. Microstrip patch antennas have the important advantage of being low profile and if the substrate is thin enough, they may also be comfortable. Basic structure of microstrip patch antenna is shown in fig1.

Antenna Polarization is very important parameter when choosing and installing an antenna. The most communications systems use either vertical or horizontal or circular polarization. Knowing the difference between polarization and how to maximize their benefits is very important to the antenna user. A linear polarized antenna radiates wholly in one plane containing the direction of propagation. In a circular polarized antenna, the plane of polarization rotates in a circle making one complete revolution during one period of the wave. An antenna is said to be vertically polarized (Linear) when its electric field is perpendicular to the Earth's surface.

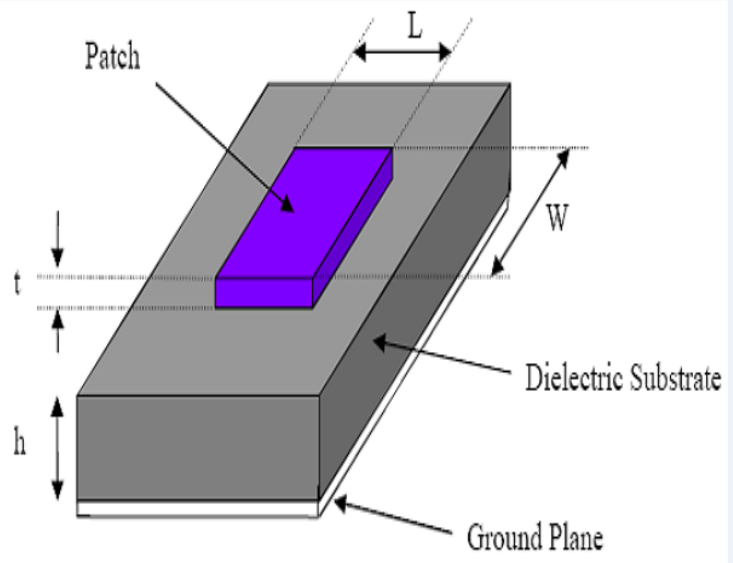

Fig.1 Micro strip patch antenna

\section{ANTENNA DESIGN}

The patch in the antenna is made of a conducting material Copper $(\mathrm{Cu})$ or Gold( $\mathrm{Au})$ and this can be in any shape like rectangular, circular, triangular, elliptical or some other common shape. The hexagonal patch antenna is designed so as it can operate at the resonant frequency. The important parameters for the design of a Hexagonal microstrip patch antenna are:

Frequency of Operation $\left(f_{r}\right)$ : The resonant frequency of the antenna is depending on the application. The presented antennas are designed for Ku-band 
applications. The frequency range of $\mathrm{Ku}$ band is approximately 12 to $18 \mathrm{GHz}$. The resonant frequency selected for this design is $15 \mathrm{GHz}$.

- Dielectric Constant of the Substrate $\left(\varepsilon_{\mathrm{r}}\right)$ : The dielectric constant of a substrate $\left(\varepsilon_{\mathrm{r}}\right)$ plays an important role in the patch antenna design. A substrate with a high dielectric constant reduces the dimensions of the antenna but it affects the antenna performance too. So, there is a trade-off between size and performance of a patch antenna. The dielectric material chosen for this antenna is FR-4 epoxy, which is having a dielectric constant of 4.4

- Height of dielectric substrate (h): For the microstrip patch antenna to be used in communication systems, it is essential that the antenna is not bulky. Hence, the height of the dielectric substrate should be less.

$$
\mathrm{h} \leq \frac{0.3 \times \mathrm{C}}{2 \times \Pi \times \mathrm{fr} \sqrt{\varepsilon r}}
$$

After the proper selection of above three parameters, the next step is to calculate the radiating patch radius and ground dimensions.

- Side of a hexagonal patch is given by

$$
\mathrm{S}=\frac{\mathrm{C}}{23.1033 \mathrm{fr} \sqrt{\varepsilon \mathrm{r}}}
$$

- Radius of hexagonal patch antenna is given by

$$
r=S \times \sqrt{\frac{2.598}{\Pi}}
$$

- Calculation of the ground plane dimensions ( $\mathrm{Lg}$ and $\mathrm{Wg}$ )

$\mathrm{L}_{\mathrm{g}}=6 \mathrm{~h}+\lambda$

$\mathrm{W}_{\mathrm{g}}=6 \mathrm{~h}+\lambda$

Where,

$$
\lambda=\frac{C}{\mathrm{fr} \sqrt{\varepsilon r}}
$$

\section{ANTENNA PARAMETERS}

Before discussing the simulation of the hexagonal microstrip patch antenna, it is important to discuss the parameters in detail that are to be analyzed in simulation.

- Return Loss: It is the difference between forward and reflected power, in $\mathrm{dB}$ If the power transmitted by the source is $P_{t}$ and the power reflected back is $P_{r}$, then the return loss is given by $\mathrm{Pr}$. The reflection coefficient is also known as s11 or return loss. For maximum power transfer the return loss should be as minimum as possible. This means that the ratio of $\mathrm{Pr} / \mathrm{Pt}$ should be as small as possible, or expressed in $\mathrm{dB}$, the return loss should be as large a negative number as possible.

- Gain: It is defined as the ratio of the intensity, in a given direction, to the radiation intensity that would be obtained if the power accepted by the antenna is radiated isotropically.

- Radiation pattern: A radiation pattern defines the variation of the power radiated by an antenna as a function of the direction away from the antenna. This power variation as a function of the arrival angle is observed in the antenna's far field. The radiation pattern is a graphical depiction of the relative field strength transmitted from or received by the antenna. Antenna radiation patterns are taken at one frequency, one polarization, and one plane cut.

- VSWR: For a radio (transmitter or receiver) to deliver power to an antenna, the impedance of the radio and transmission line must be well matched to the antenna's impedance. The parameter VSWR is a measure that numerically describes how well the antenna is impedance matched to the radio or transmission line it is connected to.

\section{PROPOSED ANTENNAS}

A. Linearly polarized dual frequency hexagonal patch microstrip antenna

The above parameters are analyzed and used in design of hexagonal patch antenna. Linearly polarized dual frequency hexagonal microstrip patch antenna is shown in Figure:2 . This antenna is designed to operate at $15 \mathrm{GHz}$. The radius of an hexagonal patch antenna is $2.75 \mathrm{~mm}$.Dimension of this antenna are $12.42 \times 12.42 \times 0.48 \mathrm{~mm}$.FR-4 epoxy is selected as substrate material, which is having dielectric constant of 4.4.The size of rectangular shaped slot is $2.4 \times 0.6 \mathrm{~mm}$.

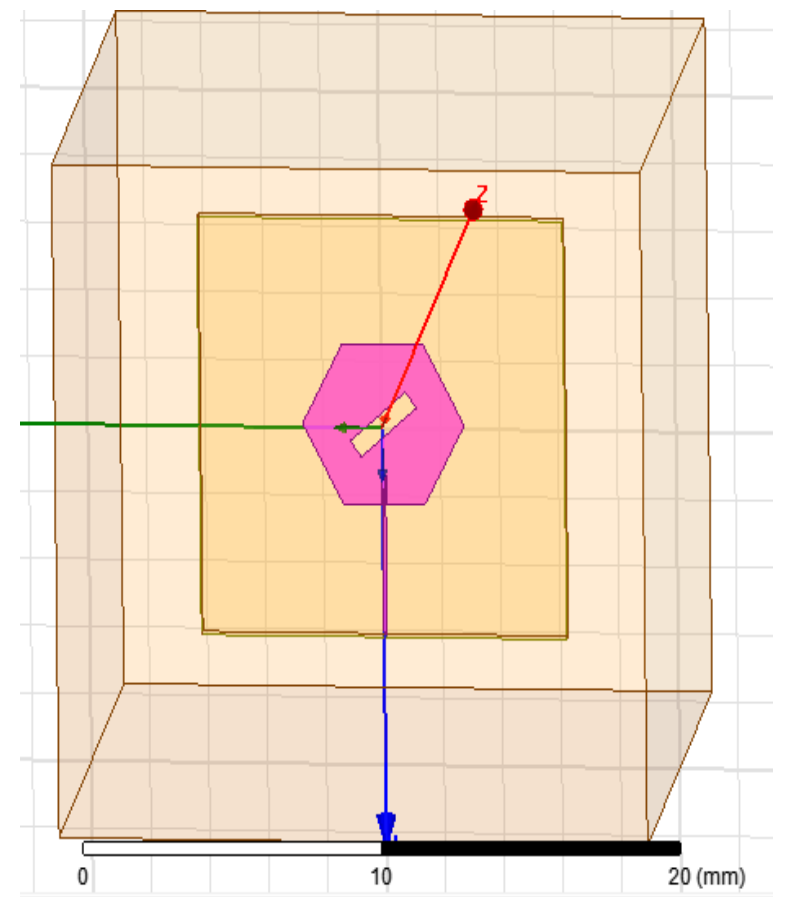

Fig.2 linearly polarized dual frequency hexagonal patch antenna

B. wide band circularly polarized hexagonal microstrip patch antenna

Wide band circularly polarized hexagonal microstrip patch antenna is shown in Figure:3. This antenna covers the frequency range in $\mathrm{Ku}$ band from $14.38 \mathrm{GHz}$ to 15.28 GHz. The radius of an hexagonal patch antenna is $2.75 \mathrm{~mm}$. Dimension of this antenna is $12.42 \times 12.42 \times 0.48$ mm.FR-4 epoxy is selected as substrate material, which is having dielectric constant of 4.4.The size of rectangular slot is $2.03 \times 0.4 \mathrm{~mm}$. 


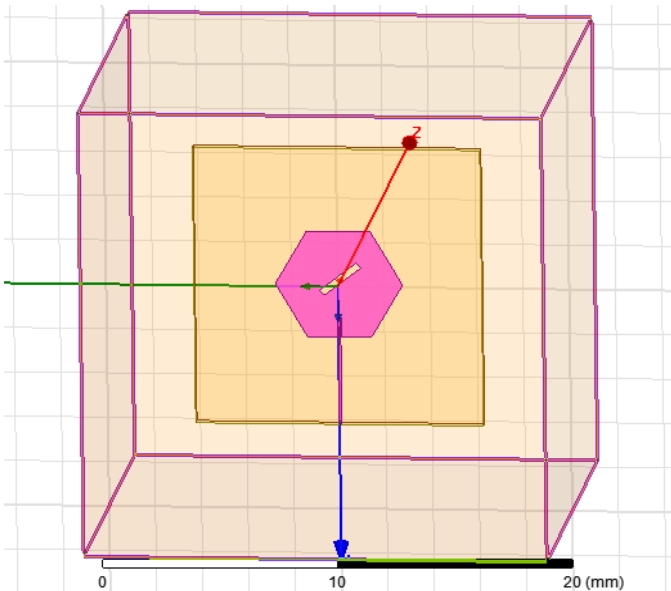

Fig. 3 circularly polarized wide band hexagonal patch antenna

\section{SIMULATION}

The simulation of these antennas is done using HFSS (High Frequency Structural Simulator) 14.0. HFSS uses finite element method (FEM) for solving electromagnetic structures and design of antennas, RF electronic circuit elements such as filters and transmission lines.

\section{RESULTS}

A. Dual frequency linearly polarized hexagonal microstrip patch antenna

The position of the slot is modified randomly until a specific return loss values $\mathrm{S} 11<-10 \mathrm{~dB}$. Return losses -20 $\mathrm{dB}$ at $13.81 \mathrm{GHz}$ and $-21 \mathrm{~dB}$ at $14.97 \mathrm{GHz}$ are observed. This antenna got over all gain of $4.4 \mathrm{~dB}$ and axial ratio of $13 \mathrm{~dB}$. Simulated results are shown in following figures.

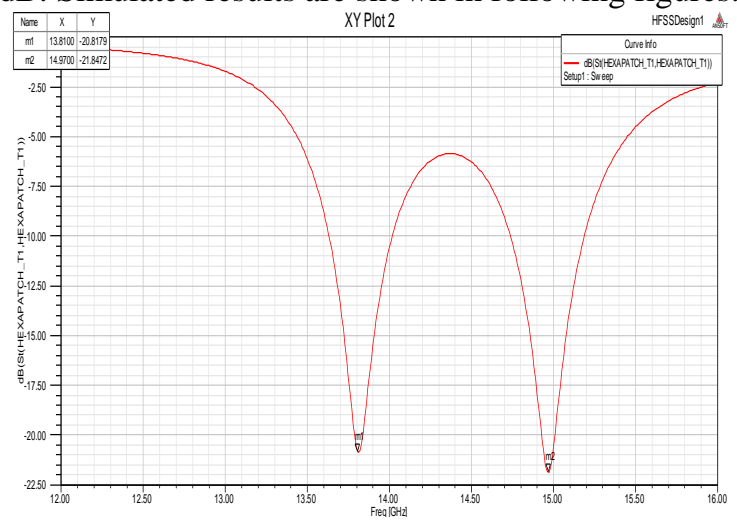

Fig.-4: Return loss plot

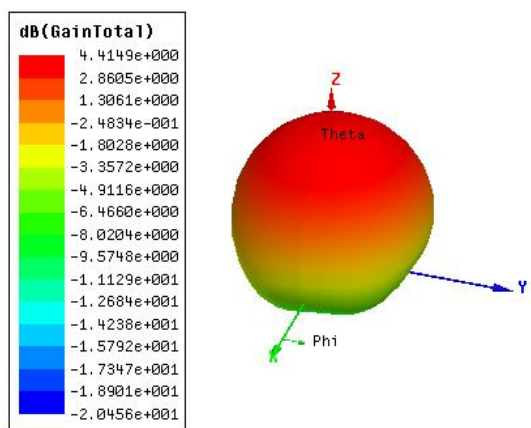

Fig-5:Gain plot

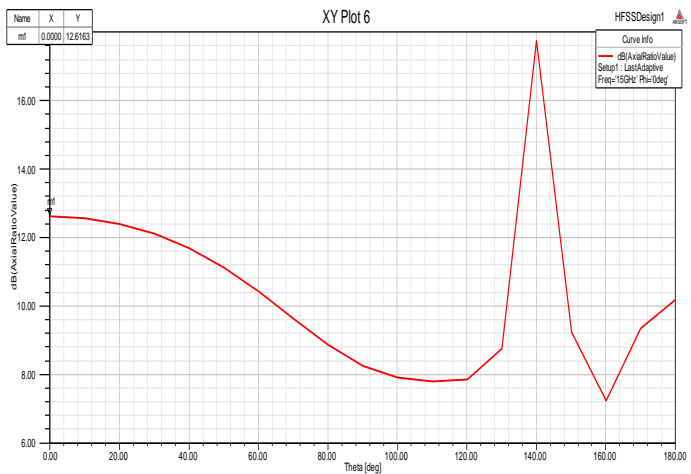

Fig-6: Axial ratio plot

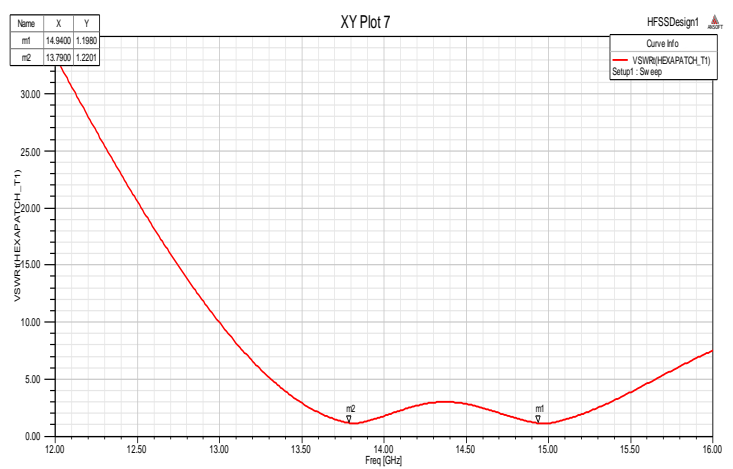

Fig-7: VSWR plot

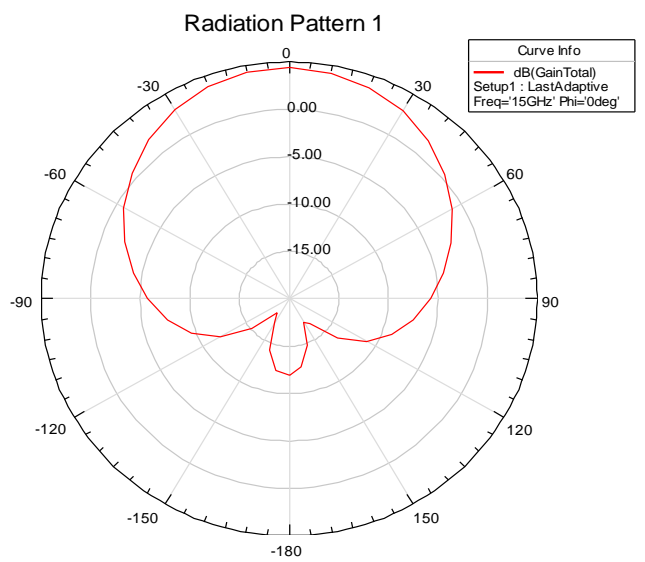

Fig-8: Radiation pattern

TABLE-1Design specifications for linearly polarized hexagonal patch antenna

\begin{tabular}{|c|c|}
\hline Type of antenna & $\begin{array}{c}\text { Dual frequency } \\
\text { Hexagonal patch } \\
\text { antenna }\end{array}$ \\
\hline $\begin{array}{c}\text { Dielectric constant of } \\
\text { substrate }\end{array}$ & FR-4 Epoxy (2.4) \\
\hline Operating frequency & $15 \mathrm{GHz}$ \\
\hline Height of substrate & $0.48 \mathrm{~mm}$ \\
\hline Feeding method & Inset feed \\
\hline Gain & $4.41 \mathrm{~dB}$ \\
\hline Polarization & Linear polarization \\
\hline Return loss & $\begin{array}{c}-20 \mathrm{~dB} \text { at } 13.87 \mathrm{GHz} \\
\text { and }-21 \mathrm{~dB} \text { at } 14.97 \\
\mathrm{GHz}\end{array}$ \\
\hline
\end{tabular}


B. Wide band circularly polarized hexagonal microstrip antenna

This wide band antenna covers frequency range from 14.38 to $15.28 \mathrm{GHz}$.Return losses $-18.6 \mathrm{~dB}$ at $14.68 \mathrm{GHz}$ and $-17 \mathrm{~dB}$ at $14.99 \mathrm{GHz}$ are observed. This antenna got over all gain of $4.37 \mathrm{~dB}$ and axial ratio of $2.77 \mathrm{~dB}$. Simulated results are shown in following figures.

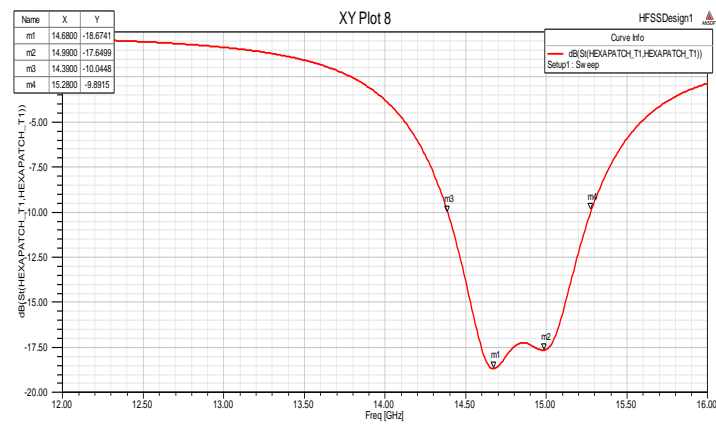

Fig-9: Return loss plot

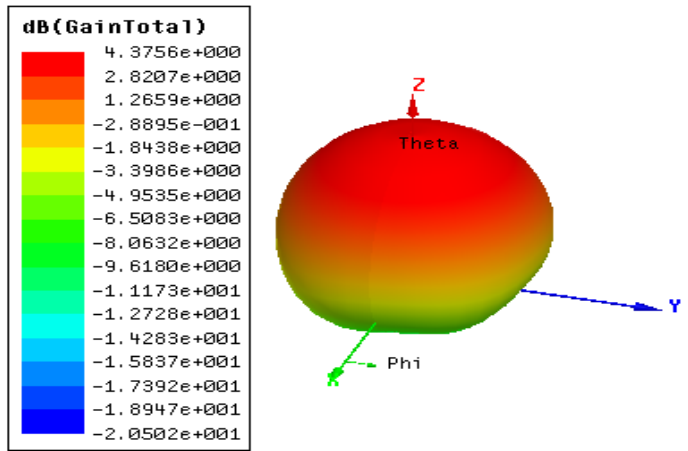

Fig-10: Gain plot

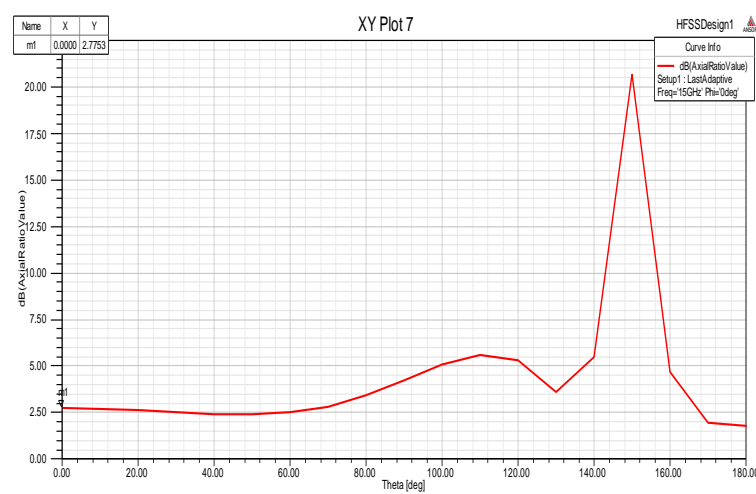

Fig-11: Axial ratio plot

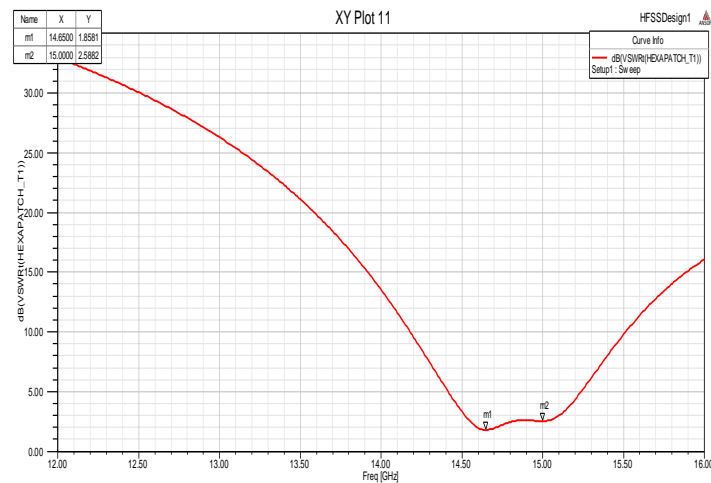

Fig-12: VSWR plot

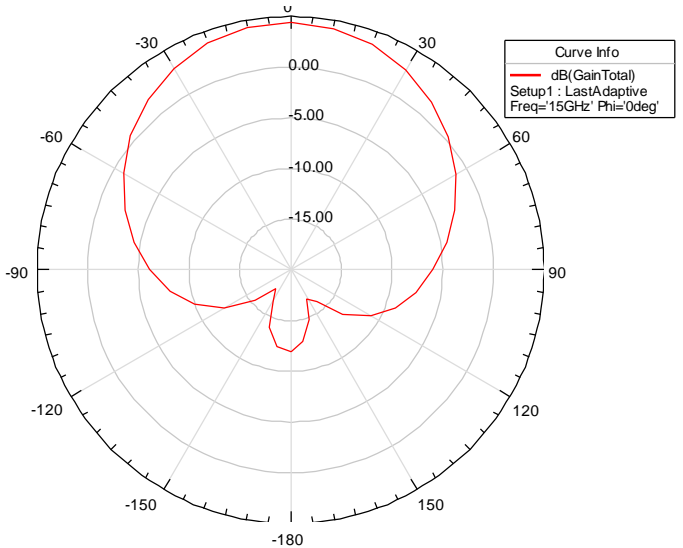

Fig-13: Radiation pattern

TABLE-2Design specifications for circularly polarized hexagonal patch antenna

\begin{tabular}{|c|c|}
\hline Type of antenna & $\begin{array}{c}\text { Wide band } \\
\text { Hexagonal patch } \\
\text { antenna } \\
\end{array}$ \\
\hline $\begin{array}{l}\text { Dielectric constant of } \\
\text { substrate }\end{array}$ & FR-4 Epoxy (2.4) \\
\hline Operating frequency & $15 \mathrm{GHz}$ \\
\hline Height of substrate & $0.48 \mathrm{~mm}$ \\
\hline Feeding method & Inset feed \\
\hline Gain & $4.3 \mathrm{~dB}$ \\
\hline Polarization & Circular polarization \\
\hline Return loss & $\begin{array}{c}-18 \mathrm{~dB} \text { at } 14.68 \mathrm{GHz} \\
\text { and }-17 \mathrm{~dB} \text { at } 14.99 \\
\mathrm{GHz}\end{array}$ \\
\hline Bandwidth & $\begin{array}{c}0.9 \mathrm{~GB}(14.3-15.2 \\
\mathrm{GHz})\end{array}$ \\
\hline
\end{tabular}

VII. CONCLUSION \& FUTURE WORK

Linear and circular polarized hexagonal microstrip patch antennas with inset feed are designed and simulated using HFSS 14.0, after that performance measures such as return loss, peak gain, VSWR, axial ratio and radiation pattern are observed. The resonant frequency selected for these antennas is $15 \mathrm{GHz}$. Linear and circular polarizations are obtained by changing the dimensions of a rectangular slot. These antennas are designed for $\mathrm{Ku}$ band applications such as satellite and radar communications. Both antennas are designed only for single band. Dual and triple bands can be carried out in future.

\section{ACKNOWLEDGEMENT}

Extending our grateful thanks to the authorities of Acharya Nagarjuna University for their support and encouragement to write this paper.

\section{REFERENCES}

[1]. David M. Pozar, Daniel H Schauber, "Microstrip Antennas: The Analysis and Design of Microstrip Antennas and Arrays", John Wiley \& Sons, 1995

[2]. Sekhar M,Siddaiah P, "Performance of Feed on Dual Frequency Antenna in Ka-Band", International Journal Of Innovative Research In Electrical, Electronics, Instrumentation And Control Engineering Vol. 2, Issue 5, May 2014.

[3]. Sanchita Basu, Ashish Srivastava, Abhishek Goswami, "Dual Frequency Hexagonal Microstrip Patch Antenna", International 
Journal of Scientific and Research Publications, Volume 3, Issue 11, November 2013, ISSN 2250-3153.

[4]. Sekhar M,Siddaiah P, "Comparison of Dual Frequency Antenna in Ka-Band with and without Shorting pin", International Journal of Modern Communication Technologies \& Research (IJMCTR), Volume-2, Issue-8, August 2014.

[5]. "Circularly Polarized Antennas" by Steven (Shichang) Gao, Qi Luo, Fuguo Zhu,Wiley 2013.

[6]. "Microstrip Antennas: The Analysis and Design of Microstrip Antennas and Arrays" edited by David M. Pozar, Daniel H. Schaubert.

[7]. "Microstrip Antenna Design Handbook" by ramesh carg 2001 artech house.

[8]. Microstrip Antennas: The Analysis and Design of Microstrip Antennas and Arrays edited by David M. Pozar, Daniel H. Schauber.

[9]. Antenna Theory: Analysis and Design (3rd Edition) (John Wiley \& Sons, 2005) Author Constantine A. Balanis [3]' Antenna and wave propagation by G.s.n Raju, Pearson Education India.

[10]. Abhishek Joshi, Sachin Singhal, Rajveer Singh "Analysis of Dual Band Circularly Polarized Microstrip Hexagonal Patch Antenna by Tuning the Feed Position",IJECT Vol. 4, Issue Spl - 4, April - June 2013.

\section{BIOGRAPHIES}

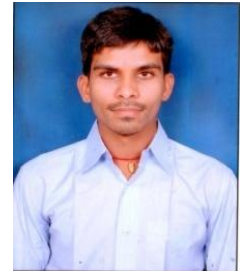

K.suresh is currently pursuing M.Tech degree in Communication Engineering and Signal Processing(CESP) from University College of Engineering and Technology, Acharya Nagarjuna University, Guntur, India. He obtained B.Tech degree in Electronics and Communication Engineering from Swarnandhra College of Engineering and Technology in 2012. His areas of interest are Antenna designing and Digital Image Processing.

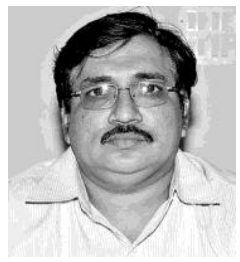

Dr. P Siddaiah obtained B.Tech degree in Electronics and communication engineering from JNTUA College of engineering in 1988.He received his M.Tech degree from SV University Tirupathi. He did his PhD program in JNTU Hyderabad.

$\mathrm{He}$ is the Chief Investigator for several outstanding Projects sponsored by Defense Organizations, AICTE, UGC \& ISRO. He is currently working as Professor \& PRINCIPAL, Department of ECE in University College of Engineering and Technology, Acharya Nagarjuna University, Guntur, India. He has taught a wide variety of courses for UG \& PG students and guided several projects. Several members successfully completed their Ph.D under his guidance. Several members pursuing their Ph.D degree. He has published several papers in National \& International Journals \& Conferences. He is the life member of FIETE, IE \& MISTE. 